\title{
Эллипсометрический метод бесконтактного in situ контроля температуры в процессах МЛЭ КРТ
}

\author{
Д.В. Марин ${ }^{1)}$, И.А.Азаров ${ }^{1,2)}$, В.А.Швец ${ }^{1,2)}$, С.В. Рыхлицкий ${ }^{1)}$, М.В. Якушев ${ }^{1)}$, Е.В. Спесивцев ${ }^{1)}$ \\ ${ }^{1}$ ИФП СО РАН, Новосибирск, 630090, пр. Ак. Лаврентьева, 13 \\ ${ }^{2}$ НГУ, 630090, г. Новосибирск, ул. Пирогова, 2 \\ тел:+7 (383) 330-5501, факс: +7(383)333-27-71, эл. почта: marin@isp.nsc.ru
}

DOI 10.34077/RCSP2019-26

Ключевым параметром, определяющим качество получаемых структур в методе молекулярнолучевой эпитаксии (МЛЭ), является температура подложки. Существуют различные методы контроля температуры в условиях низкотемпературного синтеза МЛЭ, но каждый из них имеет свои ограничения $[1,2]$, и они не решают полностью поставленную задачу. Сделанные нами ранее оценки возможности лазерной эллипсометрии для контроля температуры показали, что точность метода составляет $20-30^{\circ} \mathrm{C}$ и не удовлетворяет требованиям технологии [2].

B данной работе предложен метод in situ контроля предростовой температуры CdTe на основе спектральной эллипсометрии, чувствительность которого на порядок превышает приведённую выше оценку. Для этого нами разработан, изготовлен и смонтирован на модуль роста КРТ спектральный эллипсометр ( $\lambda=350-1100$ нм), конструкция которого оптимизирована под геометрию используемой вакуумной камеры.

Для измерения температуры используются характеристики спектров $\Psi(\lambda)$ и $\Delta(\lambda)$ вблизи критических точек зонной структуры СdTe, соответствующих краю поглощения $\mathrm{E}_{0}\left(\lambda_{0(300 \kappa)} \approx 830\right.$ нм) и межзонному переходу $\mathrm{E}_{1}\left(\lambda_{1(300}\right.$ к) $\approx 370$ нм). Вблизи $\mathrm{E}_{0}$ появляются интерференционные осцилляции $\Psi$ и $\Delta$, а вблизи $\mathrm{E}_{1}$ наблюдается максимум в спектре $\Psi(\lambda)$. Спектральное положение критических точек зависит от температуры. Проведённая нами предварительно ex-situ калибровка на образцах CdTe показала, что чувствительность составляет $0.22 \mathrm{Hм} /{ }^{\circ} \mathrm{C}$ для $\mathrm{E}_{0}$ и $0.067 \mathrm{Hм} /{ }^{\circ} \mathrm{C}$ для $\mathrm{E}_{1}$. Предложен метод определения $\mathrm{E}_{0}$ по затуханию амплитуд интерференционных осцилляций, который позволяет находить значение $\lambda_{0}$ с точностью 0.5 нм, что соответствует точности определения температуры $3^{\circ} \mathrm{C}$.

На рисунках показаны фрагменты спектров $\Psi(\lambda)$ вблизи указанных критических точек, измеренные in situ: при комнатной температуре $\left(\mathrm{T}_{1}\right)$, при температуре отжига подложки $\left(\mathrm{T}_{3}\right)$ и перед началом эпитаксиального роста КРТ $\left(\mathrm{T}_{2}\right)$. На вставках приведены спектральные положения максимумов $\Psi$ и начала интерференционных осцилляций. Амплитуды интерференционных осцилляций показаны жирными точками. Наблюдается корреляция температурных изменений спектров в УФ и ИК областях.
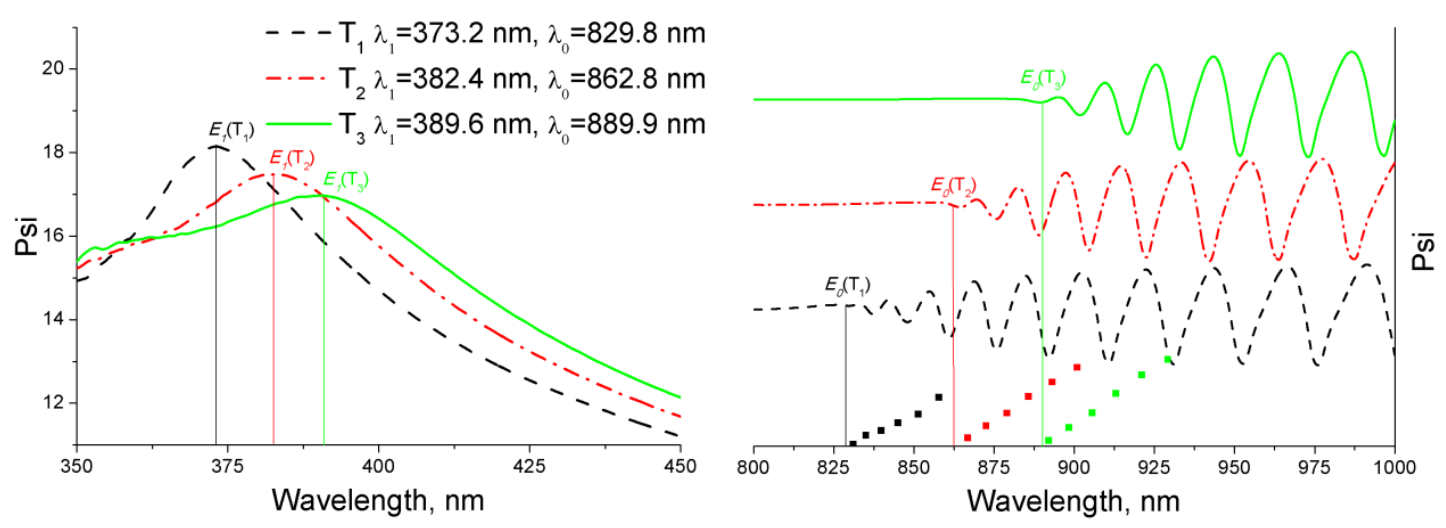

\section{Лuтература}

[1] А.Н. Магунов, Лазерная термометрия твердых тел, Физматлит, М., 2002

[2] И.А. Азаров и др. Фотоника 2017. Тез. Докладов, Новосибирск, с. 119. 